\title{
PESQUISA DE EMPREGO E DESEMPREGO sua importância como metodologia de pesquisa
}

\author{
Paula Montagner
}

Atsuko Haga

\begin{abstract}
Resumo: A importância da desenvolvimento da Pesquisa de Emprego e Desemprego - PED para a Região Metropolitana de São Paulo ultrapassa a capacidade de gerar informações sobre um mercado de trabalho heterogêneo. Além da inovadora construção teórica, a PED criou uma metodologia de dados que complementa as percepções dos analistas e que pode ser reproduzida para outros temas e localidades.

Palavras-chave: pesquisa domiciliar; mercado de trabalho; coleta de informações.

Abstract: The importance of the development of the Survey on Employment and Unemployment - PED - for the São Paulo Metropolitan Area goes beyond the capacity to generate information about the heterogeneous labor market. Aside from the innovative theoretical construction, the PED created a data methodology that complements the perceptions of analysts and that can be adapted to other subjects and locations.

Key words: household research; labor market; data gathering.
\end{abstract}

A realização de uma pesquisa domiciliar contínua é uma das experiências marcantes pelas quais a Fundação Seade, e seu corpo técnico e diretivo, têm passado nos últimos 20 anos. A relativa unanimidade do papel fundamental que essa pesquisa teve para a definição dos rumos dessa instituição, que mantém destacado papel na geração de informações sociais, demográfica e econômicas, decorre da percepção de que apenas adquirindo o domínio da elaboração de metodologias e da tecnologia de produção de informação, as instituições públicas podem cumprir seu papel de gerar informações de qualidade destinadas a subsidiar políticas públicas e apoiar o funcionamento pleno da cidadania.

Este artigo procura demonstrar como a realização da Pesquisa de Emprego e Desemprego - PED permitiu não apenas o desenvolvimento de uma metodologia inovadora quanto às questões do trabalho, mas também estruturar um conjunto de pesquisas quantitativas, que podem ser adaptadas e reproduzidas em diferentes localidades, para diferentes temas socioeconômicos.

Os motivos que levaram o governo do Estado de São Paulo, no início dos anos 80 , a combinar esforços mediante parceria de pesquisadores do setor público, de universidades e de entidades de pesquisa ligadas ao movimento sindical, para a realização de uma pesquisa domiciliar contínua na Região Metropolitana de São Paulo, são relativamente conhecidos. Como decorrência da profunda crise econômica dos dois primeiros anos da década de 80 , havia um considerável descompasso entre as estatísticas oficiais de desemprego e a demanda por postos de trabalho da população na região. A tensão social do período manifestou-se de forma organizada, por meio do apoio dos sindicatos combativos que buscavam ativamente sua reorganização e a articulação com autoridades do governo estadual - que representavam grupos políticos mais progressistas -, mas também por manifestações sociais menos organizadas, tal como o saque a supermercados e a outras formas de comércio em áreas em que se concentravam as pessoas que procuravam trabalho sem encontrar. Com efeito essa era a primeira crise urbana experimentada no país depois de quase 40 anos de crescimento praticamente ininterrupto e ocorria na área mais fortemente industrializada do país, invertendo assim o sinal de atração populacional que fora uma de suas mais fortes marcas da década anterior.

Inicialmente buscava-se apenas acesso a informações sobre a questão do desemprego, de modo que se pudesse 
quantificar o número de desempregados e seu perfil e avaliar a necessidade de postos a serem gerados. No entanto, as primeiras experiências de coleta e análise das informações realizadas pelo Dieese, conforme suplemento de pesquisa de orçamentos familiares do Município de São Paulo - PPVE (Dieese, 1984), sugeriam que a heterogeneidade de situações encontradas mereciam aprofundamento analítico, a fim de bem descrever o desemprego maciço, fenômeno inédito no cenário nacional, e também as diferentes formas de inserção encontradas entre os que ainda não eram assalariados.

O desenvolvimento da nova metodologia para conceituar as situações de trabalho e de desemprego/desocupação foi uma decorrência da experiência vivida no início dos anos 80 , mas que não se refletia nas estatísticas oficiais, que seguiam as normas preconizadas pela OIT, estabelecidas no início dos anos 50, para a coleta de informações sobre o emprego, que tem por modelo países em que o assalariamento de há muito constituía a forma largamente majoritária de inserção ocupacional, sendo usual acordos que determinavam o número de horas trabalhadas similar para as várias categorias de trabalhadores e uma escala salarial em que as diferenças não eram excepcionalmente elevadas. As possibilidades de ocupação naquele período do pós-guerra eram relativamente simples, pois nas áreas em que havia investimentos para a reconstrução de infra-estrutura faltava mão-de-obra, e a permanência em situação de desemprego era curta, e naquelas em que o crescimento era menor, havia a possibilidade de migrar para áreas em que a situação permitia trabalhar e gerar melhores condições de vida.

A reprodução das recomendações internacionais decorrentes desse contexto social e econômico particular impunha problemas para sociedades e economias como as latino-americanas em que a industrialização era recente e, em muitos casos, envolvia apenas alguns tipos de atividades. $\mathrm{O}$ crescimento econômico experimentado pelo Brasil representava um caso particular, pois, em pouco mais de 40 anos, a população havia experimentado grande transformação, passando de majoritariamente rural (dois terços, segundo o Censo Demográfico de 1940), para majoritariamente urbana (dois terços da população, Censo Demográfico de 1980). No entanto, essa transformação era espacialmente desigual, com crescente concentração de atividades econômicas e populacionais na Região Sudeste, enquanto a Região Nordeste permanecia desindustrializada, economicamente dependente de atividades agrárias, e com um grande segmento populacional em pro- priedades de pequeno porte, que mal proviam a subsistência de seus moradores. Com o crescimento da necessidade de mão-de-obra no Sudeste, essa população pobre e com baixa escolaridade migrou para o Sudeste em busca de melhores condições de vida, encontrando trabalho nas atividades urbanas, na indústria, na construção civil, comércio e prestação de serviços.

O trabalho encontrado, no entanto, nem sempre correspondia ao assalariamento, reproduziam-se nas áreas urbanas experiências de informalidade dos vínculos que eram comuns nas áreas rurais, ao arrepio da lei, que não era suficientemente fiscalizada. Nos anos 70 , acreditavase que esse era um mal menor diante da elevada rotatividade da mão-de-obra que, em geral, permitia trajetórias ascendentes à maioria dos trabalhadores.

A crise dos anos 80 interrompeu esse processo, evidenciando os aspectos negativos, como: demissões sem justa causa por parte dos empregadores; utilização do processo inflacionário para invalidar o crescimento dos salários, mantendo a participação destes como uma parcela reduzida do custo de produção. No entanto, naquele período, não apenas se interrompia a dança das cadeiras, mas algumas deixaram de existir e com isso parcela expressiva da população deixou de ter emprego em que pese esta nova situação, a figura do desempregado, enquanto grupo social, era, pode-se dizer, inexistente. As pessoas que viviam na Região Sudeste, em especial na Região Metropolitana de São Paulo, a desconheciam, pois uma realidade diferente havia conformado as duas últimas décadas a figura do desempregado não era uma designação facilmente admitida, ao contrário do que supunham as metodologias utilizadas para mensurar a situação de desemprego.

Entre os elementos novos trazidos pela PED, destacase a utilização dos procedimentos operacionais, que passaram a ser adotados pela OIT a partir dos anos 80 (ILO, 1983), para o desemprego aberto, ao tomar como referência o período de 30 dias anterior à pesquisa e não apenas o de sete dias que havia sido utilizado até então, mas que já se mostravam insuficientes para caracterizar situações de desemprego em países industrializados, que haviam passado por recente período de desaceleração de suas atividades econômicas, com elevação de preços e crise em suas matrizes energéticas, devido ao aumento do petróleo imposto pelos países produtores na segunda metade dos anos 70 .

Aproveitando a flexibilidade contemplada pelas recomendações internacionais da OIT, a PED passou também 
a identificar os indivíduos que estavam desalentados, pois tendo procurado trabalho por um longo período haviam percebido que não havia espaço para sua inserção no mercado de trabalho e deixavam de fazer procura de trabalho, embora reconhecessem sua necessidade e disponibilidade de tempo para trabalhar.

De forma crítica aos procedimentos usuais no país e às próprias normas internacionais, buscou-se resgatar uma parcela da população que realizava alguma atividade remunerada com ganhos avulsos, descontínua e instável, enquanto procurava por um novo trabalho, situação típica da realidade do nosso mercado de trabalho, marcado por grande heterogeneidade e elevada concentração de renda, que dificultam a sobrevivência dos trabalhadores nos períodos de desemprego. Ainda hoje, é fundamental insistir que essas pessoas não desejam continuar nessa situação, posto que sabem da descontinuidade e precariedade da atividade exercida e buscam efetivamente um posto de trabalho que lhes permita alterar sua condição de inserção no mercado de trabalho.

Desta forma, a PED passou a identificar três situações de desemprego: desemprego aberto com procura de trabalho aferida nos últimos 30 dias; desemprego oculto pelo desalento; e desemprego oculto pelo trabalho precário, que constituem o conjunto dos desempregados.

Para uma adequada captação dessas três situações diferenciadas de desemprego, foi fundamental bem definir os parâmetros classificatórios da condição de atividade da população em idade ativa, ou seja, da população em idade de trabalhar.

Em mercados de trabalhos heterogêneos, existe um obscurecimento dos limites que separam as situações de trabalho - com ou sem vínculo formalizado - das situações de não trabalho, e de procura e não procura de trabalho, que deviam ser traduzidas na classificação dos indivíduos como ocupados, desempregados ou inativos, que por envolver hipóteses simplificadoras dessa realidade tendem a privilegiar a classificação dos indivíduos como ocupados.

Vencer esses obstáculos conduziu à formulação de um questionário diferente do habitual, evitando que o entrevistado fosse classificado a partir de uma única questão, utilizando apenas a combinação dos parâmetros mencionados (trabalho e não trabalho, procura e não procura) (Fundação Seade - Dieese, 1995). Pelo contrário, investiga-se com detalhes a procura de trabalho (providências tomadas e motivos da procura, bem como a disponibilidade para trabalhar) e suas diversas formas de associação com o exercício de trabalho, privilegiando-se a identificação das formas de trabalho descontínuas/instáveis de auto-ocupação para redefinir as fronteiras dos subconjuntos de trabalhadores ocupados, desempregados e inativos.

Uma vez identificadas as três situações de condição de atividade, detalham-se, para os ocupados, informações sobre as características dos seus postos de trabalho e dos rendimentos auferidos; para os desempregados, as características do seu último trabalho e os meios de sua sobrevivência; e, para os inativos, a principal situação de inatividade. Adicionalmente são caracterizadas as atividades/ trabalhos eventuais realizados pelos desempregados ou inativos nos últimos 30 dias, que permitem não só confirmar a captação da sua condição de atividade, como também preservar as variáveis mínimas para caracterização do trabalho exercido.

Definidas as questões anteriores, um novo conjunto de decisões se impunha: como coletar essas informações com qualidade e agilidade numa pesquisa contínua com divulgação mensal. Entre os problemas mais conhecidos das pesquisas quantitativas, na área socioeconômica, este permanece sendo o que merece destaque, pois exige elaborados procedimentos a serem perseguidos por toda equipe, em especial dos pesquisadores de campo, na tentativa de enquadrar a multiplicidade do real vivida pelas pessoas entrevistadas e as simplificações necessárias para fins classificatórios.

A solução encontrada foi dupla: por um lado, buscou-se um desenho de questionário que combinasse, para algumas questões, a possibilidade de descrição da resposta do entrevistado e o seu enquadramento nas alternativas pré-codificadas; por outro, estabeleceu-se um sistema de controle de qualidade, que perpassa todas as atividades no âmbito da pesquisa, sustentado por um trabalho interativo das diversas equipes de campo e apoiado por manuais (pesquisador, supervisor, crítica, checagem e consistência eletrônica) que orientam essas atividades, bem como uma discussão metodológica permanente de situações particulares, não previstas nas codificações das respostas às questões levantadas, e consistência eletrônica dos dados.

Um sistema informatizado de controle de atividade de campo permite acompanhar diariamente o aproveitamento da amostra, de tal forma a garantir ao final do levantamento mensal a representatividade desejada das informações levantadas.

A equipe responsável pela coleta da PED é incentivada a recolher informações adicionais que considerar mais 
relevantes nos domicílios em que realiza as entrevistas. Essas são avaliadas pelas equipes responsáveis pela execução da coleta de dados e pela aplicação da metodologia da pesquisa para o correto tratamento/enquadramento do caso diferenciado, descrito de acordo com os critérios classificatórios da pesquisa, expressos nos seus instrumentos de coleta. Este procedimento permite um saudável debate entre entrevistadores, críticos, analistas, estatísticos e integrantes do grupo metodológico, sobre as situações inusitadas que o campo recolhe.

Após muitos anos de pesquisa, são conhecidos os casos de situações em que a percepção de que havia alterações em curso no mercado de trabalho regional decorreu de informações que foram constatadas inicialmente entre os entrevistadores e cuja generalização levou a que novas codificações fossem estabelecidas para medir a importância do fenômeno observado. Como esperado, na maioria dos casos, tratava-se de situações particulares que não atingiam parcelas significativas da população.

A capilaridade representada pela interação do entrevistador com entrevistados e os demais profissionais que integram a equipe de pesquisa representam, sem prejuízo da objetividade dos critérios de classificação, a sempre saudável interação entre as equipes com suas variadas expertises e a realidade social que se pretende apreender e mensurar, mediante conceitos e indicadores, que tendem a ser preservados ao longo do tempo, para garantir séries históricas que são a base de estudos estatísticos que envolvem modelagem simplificadora da realidade concreta.

Ao longo dos anos foi possível, com a experiência da PED-RMSP, garantir um conjunto de desdobramentos, alguns esperados, como a possibilidade de trazer novos aspectos para o âmbito da investigação, por exemplo em suplementos especiais.

A existência da PED permitiu a notável possibilidade de rapidamente avaliar a introdução de uma nova legislação de contratação por tempo determinado (1998), uma captação mais abrangente dos rendimentos individuais e familiares e acesso a programas sociais (Informações Complementares sobre Rendimentos e Acesso a Programas Sociais - 1999, Informações Complementares sobre Renda - 2003) e um suplemento sobre mobilidade ocupacional da PIA (População em Idade Ativa com Experiência de Trabalho nos Anos 90 - 1996). Ainda nesse campo podem ser contabilizadas as experiências de atendimento a demandas de outras secretarias de Estado e outras instituições públicas que buscavam informações específicas para melhor atender o público. Destacam-se estudos realizados em São Paulo sobre: acidentes de trabalho (Informações Suplementares sobre Acidente de Trabalho - 1994); a situação dos jovens estudantes e recémegressos do ensino médio e suas ambições de continuidade de formação escolar e necessidades de capacitação (Informações Suplementares sobre Formação Profissional 1997); o novo perfil demandado pelos empregadores em termos de requisitos de seleção e contratação (Informações Suplementares sobre Formação Profissional - 1997); e o estudo sobre acesso e uso da Internet por parte da população metropolitana e suas demandas para sites públicos (Hábitos de Leitura, Acesso e Usos da Internet 2001).

A existência da PED e o reconhecimento de sua metodologia propiciaram também a possibilidade de participar de uma pesquisa comparativa internacional, em que pesquisadores de outros países - França, Japão e Brasil buscam comparar as semelhanças e as diferenças entre os desempregados e as trajetórias de seus ocupados para averiguar a importância das experiências regionais e de suas diferentes instituições, tal como as agências de intermediação de mão-de-obra e outras políticas de emprego e proteção social, com a inclusão de um novo suplemento especial sobre mobilidade ocupacional (Informações Complementares sobre Mobilidade Ocupacional da PIA com Experiência nos Últimos Oito Anos - 2001).

Um desdobramento de certa forma menos esperado foi a reprodução da metodologia PED em outras regiões do país. Há, nesse caso, experiências amplamente exitosas como as de Porto Alegre, Salvador, Recife, Belo Horizonte, Distrito Federal e aquelas que por interferências externas, em geral de ordem financeira, foram menos favoráveis, como as de Curitiba e Belém. Em todas essas regiões, no entanto, a situação de emprego e desemprego da população urbana foi investigada e incorporados aspectos regionais relevantes.

Com o reconhecimento da PED como parte do sistema nacional de informações sobre o trabalho por parte do Conselho do Fundo de Amparo do Trabalhador, que financia parte dos custos dessa pesquisa, um novo estágio foi almejado e vem sendo construído desde então, com a articulação de ações das diferentes equipes regionais a fim de que haja um crescente ajuste de tempos e de temas de análise, além da troca crescente de experiências, para que se possa construir de fato, um sistema de informações regionalizado e capacitado a apoiar políticas públicas com desenho nacional e local. Este sem dúvida é um dos grandes desafios de nossas equipes que para atingir esse fim 
devem avançar nos processos de integração, tanto nos métodos de trabalho, quanto nos projetos analíticos, além da integração de suas bases de dados regionais.

Um outro aspecto importante que merece ser destacado com relação à PED, é a possibilidade de aprofundamento analítico sobre aspectos especiais da estrutura do mercado de trabalho metropolitano, além do acompanhamento mensal da sua evolução conjuntural. A amostragem da pesquisa (objeto de artigo específico) propicia a acumulação de dados e permite que aspectos estruturais do mercado de trabalho e fenômenos raros sejam objeto de estudos específicos. Há, pelo menos, alguns segmentos populacionais que vêm sendo motivo de recorrente estudo ao longo dos anos: a inserção da mulher no mercado de trabalho; a situação da população de raça/cor negra; os jovens; os migrantes; os arranjos familiares; os ocupados com menor rendimento; e alguns grupos ocupacionais formados pelos ocupados nas indústrias metalúrgicas, têxtil e vestuário e os bancários, que têm sido objeto de análise ao longo dos anos, principalmente por parte de pesquisadores universitários, mas também pelos sindicalistas que negociam as pautas de reivindicações desses trabalhadores.

No caso das situação das mulheres, a demanda social crescente por informações, associada à presença de financiamento internacional, propiciada pelo Fundo para a Igualdade de Gênero, do Canadá, originou um conjunto de publicações que sistematiza as informações sobre a inserção da mulher no mercado de trabalho regional, disseminando a necessidade de gerar igualdade de oportunidade de trabalho e de remuneração para ambos os sexos e com isso melhorando a qualidade do debate em curso para uma sociedade mais justa e eqüitativa, também do ponto de vista dos gêneros, esperando-se que venha a ser possível avançar igualmente, pelo menos quanto à sistemática disseminação que diz respeito à situação desigual entre pessoas de cor negra e não-negra.

Dos estudos especiais realizados pela PED que já evidenciavam a estreita relação entre inserção no mercado de trabalho e desigualdades sociais e a percepção de que a renda não era a única dimensão da pobreza, surgiu a possibilidade de um entendimento multidimensional, deste fenômeno ainda no final dos anos 80. A corrosão dos rendimentos do trabalho, propiciada pelas elevadas e recorrentes variações dos preços que caracterizavam os anos 80 , e a tentativa de estabelecer novas bases para políticas sociais compensatórias, destinadas a diminuir para toda a população as dimensões mais notórias da desigualdade de oportunidades, obrigavam a construção de instrumentos de coleta adequados a novos indicadores. Provêm, pelo menos parcialmente, dessas percepções as pistas que levaram à formatação e execução da Pesquisa de Condições de Vida - PCV, realizada em 1990, 1994 e 1998, pela Fundação Seade, apoiada grandemente nas experiências metodológicas e de execução adquiridas com a PED.

Do ponto de vista metodológico, pode-se dizer que nesta pesquisa se manteve a pressuposição de que deveria ser possível agregar às informações usuais as que averiguavam situações locais não generalizáveis, expandindo conceitos para além dos marcos típicos das pesquisas internacionais, intencionalmente buscando caracterizar aspectos novos que haviam se tornado essenciais para a compreensão das necessidades e carências da população menos favorecida. Em vez de partir para elementos sintéticos, o final dos anos 80 já faziam antever a necessidade de procurar novos aspectos para as questões centrais das carências da população. Foi um período de estimulante avanço para expandir a compreensão do trabalho e da renda, em quadro mais amplo de necessidades sociais, em que se destacam a educação, a saúde e a habitação, em especial.

A PCV nos seus levantamentos periódicos também proporcionou a coleta de informações sobre outros aspectos relevantes, como: acidentes de trabalho e doenças profissionais; associativismo; violência e vitimização; e deslocamentos urbanos para as atividades de trabalho e estudo.

O levantamento de informações sobre acidentes de trabalho e morbidade na PCV (1994) indicaram ainda a ocorrência de acidentes de trajeto e de trabalho entre os trabalhadores com vínculo informalizado, para os quais, em geral, não ocorre a informação do acidente, uma vez que os empregadores tendem a não preencher a notificação da ocorrência. Com efeito, o número estimado de acidentes seria o dobro daquele oficialmente notificado, observando-se incidência similar entre empregados com vínculo formalizado e entre os trabalhadores sem vínculo formalizado.

Com a experiência acumulada por equipes crescentemente especializadas em geração de metodologia de pesquisa, estatística e análise na PED e mais recentemente na PCV, foi possível aos técnicos da Fundação Seade participarem também de novos tipos de pesquisas demandadas por outros organismos fora do âmbito estadual, tal como foi o caso das pesquisas sobre saúde e acidentes de motoristas de ônibus nas regiões de São Paulo e Belo Horizonte, demanda pela Fundacentro - Fundação para a Saúde do Trabalhador. Em ambos os casos, foram reali- 
zadas junto a motoristas pesquisas que permitiram avaliar os principais problemas de saúde e de trabalho dessa categoria que, sendo vital para a ampliação do volume e da qualidade do transporte público, permanece entre aquelas em que mais claramente se manifestam problemas de saúde ocupacional, decorrentes das condições do exercício do trabalho, em veículos que nem sempre se encontram em condições ideais, resultando além dos conhecidos problemas osteomusculares, graves problemas de surdez e outros de ordem física e psíquica.

O impacto dessas pesquisas foi importante, uma vez que, combinadas com aquelas realizadas com outros profissionais do transporte (motoristas de táxi, caminhões e motocicletas), elucidaram bem as transformações a serem implementadas nos transportes públicos e alertaram para o crescimento da violência, uma vez que, pelo menos, $35 \%$ desses profissionais, em ambas as regiões, tinham passado por uma situação de assalto armado em seu veículo, nos doze meses anteriores à pesquisa.

A participação e a experiência adquirida pela Fundação Seade no desenvolvimento de pesquisas de campo, como a PED e mais recentemente a PCV, foram e continuam fundamentais para que outros levantamentos de informações primárias sejam realizados, com a finalidade de gerar indicadores de novos e velhos problemas enfrentados pelos trabalhadores e pela população em geral inseridos em uma realidade sujeita a constantes transformações.

Para melhor compreensão dessas situações, como também para subsidiar a formulação e a avaliação de políticas públicas relacionadas, cabe destacar alguns exemplos destas possibilidades de pesquisas específicas já realizadas pela Fundação Seade, tais como: levantamento nacional de informações sobre execução e resultados de Telecursos para subsidiar a avaliação do programa de ensino à distância (Avaliação Externa e Acompanhamento de Egressos do Telecurso 2000 - 2000/2001); avaliação e acompanhamento da participação do jovem e da empresa contratante no programa jovem cidadão - meu primeiro trabalho (Avaliação do Programa Jovem Cidadão - Meu Primeiro Trabalho - início em 2000); cadastramento de entidades da sociedade civil que atuam na região Leste do Município de São Paulo (Cadastro de Entidades Sociais sem Fins Lucrativos - Zona Leste do Município de São Paulo - 2001); cadastramento de entidades sociais que atuam na área cultural ou esportiva na Região Metropolitana de São Paulo (Cadastro de Entidades Sociais que Atuam na Área Cultural ou Esportiva na RMSP - 2001); levantamento de informações sobre os usuários dos diversos programas habitacionais da CDHU para subsidiar as ações de planejamento habitacional do Governo do Estado de São Paulo (Levantamento Cadastral e Pesquisa Socioeconômica - Programa de Atuação em Cortiços - PAC - 2000/2001/2002; Cadastramento Socioeconômico e Levantamento Físico/Cadastral - Vila Pantanal - 1998; Mapeamento dos Setores, Pichação e Aplicação da Pesquisa Socioeconômica das Favelas de União de Vila Nova e Vila Nair - 1999/2002; Pesquisa de Situação Pós-Ocupacional - 1999; entre outros); levantamento censitário de informações do funcionalismo municipal de São Paulo relacionadas a seu perfil, avaliação dos procedimentos e locais de trabalho (Censo do Funcionalismo Público - 2002); informações sobre os deslocamentos da população residente na Região Metropolitana de São Paulo, para subsidiar a avaliação da política de transporte metropolitano (Aferição da Pesquisa Origem e Destino na RMSP - 2002).

Por último, cabe mencionar a participação da Fundação Seade na produção de informações primárias para o projeto Fábrica de Cultura integrante do Programa Cultura e Cidadania para Inclusão Social - PCCIS desenvolvido pela Secretaria de Estado da Cultura do Governo de São Paulo, com a parceria do Banco Interamericano de Desenvolvimento - BID.

Os fundamentos que permitem acreditar nesse tipo de afirmação encontram-se na reiterada possibilidade de reproduzir procedimentos que garantam a qualidade das informações coletadas e analisadas e na ousadia de não se limitar aos indicadores consagrados, mas na permanente experimentação, o que garante a possibilidade de que os membros das equipes possam ser integrados com base em suas idéias, garantindo que as experiências venham a ser postas a serviço do conhecimento comum.

\section{REFERÊNCIAS BIBLIOGRÁFICAS}

BALTAR, P.E.A. Estagnação da economia, abertura e crise do emprego urbano. Campinas: Unicamp-IE-Cesit, 1996. Mimeografado.

BALTAR, P.E.A.; DEDECCA, C.S.; HENRIQUE, W. Mercado de trabalho e exclusão social no Brasil. In: OLIVEIRA, C.A.B.; MATTOSO, J.E.L. Crise e trabalho no Brasil: modernidade ou volta ao passado? São Paulo: Scritta, 1996.

BESSON, J.L. As estatísticas: verdadeiras ou falsas? In: BESSON, J.L. (Org.). A ilusão das estatísticas. Tradução Emir Sader. São Paulo: Editora da Universidade Estadual Paulista, 1995.

BRANDÃO, S.M.C. Medição do desemprego em mercado de trabalho heterogêneo: a experiência da Pesquisa de Emprego e Desemprego - PED. Rio de Janeiro, Ipea: out. 1997 (Série Seminário 15/97). 
CÉZARD, M. Le chômage et son halo. Economie et statistique. Paris, n.193-4, 1986.

CEPAL - COMISSÃO ECONÔMICA PARA AMÉRICA LATINA E CARIBE. La medición del empleo y de los ingressos en areas urbanas a traves de encuestas de hogares. Santiago do Chile: Cepal, Informe Final do Grupo de Trabalho, agosto 1979.

COMTE, M. Três milhões de desempregados. In: BESSON, J.L. (Org.). A ilusão das estatísticas. Tradução Emir Sader. São Paulo: Editora da Universidade Estadual Paulista, 1995.

DEDECCA, C.S. Desemprego e regulação no Brasil hoje. Campinas: Unicamp-IE-Cesit, 1996. (Cadernos do Cesit n. 20).

DIEESE. Pesquisa de Emprego e Desemprego na Grande São Paulo: conceitos, metodologia e principais resultados (1981-1983). São Paulo: jul. 1984.

FUNDAÇÃO SEADE - DIEESE. Pesquisa de Emprego e Desemprego - Relatório metodológico. São Paulo: Fundação Seade, 1995. Mimeografado.

HOFFMANN, M.P.; BRANDÃO, S.M.C. Medição do emprego: recomendações da OIT e práticas nacionais. Campinas: Unicamp-IECesit 1996. (Cadernos do Cesit n. 22).

HOFFMANN, M.P.; COSTA, P.L.; SANCHES, S. Pesquisa de Emprego e Desemprego em seis regiões metropolitanas. Porto Alegre, FGTAS/SINE-RS, 2002.

HUSSMANNS, R.; MEHRAN, F.; VERMA, V. Surveys of economically active population, employment, unemployment and underemployment: an ILO manual on concepts and methods. Geneva: International Labour Office, 1990.

INTERNATIONAL LABOUR ORGANIZATION - ILO. Resolution concerning statistics of the economically active population, employment, unemployment and underemployment (Resolution I).
In: THIRTEENTH INTERNATIONAL CONFERENCE OF LABOUR STATISTICIANS. Geneva: ILO, 1983.

MENDONÇA, S.E.A.; HOFFMANN, M.P. Pesquisa de Emprego e Desemprego - PED: inovações metodológicas. In: DIEESE (Org.). Emprego e desenvolvimento tecnológico: processos de integração regional. São Paulo, 1999.

POK, C.; TRABUCHI, C.C. Encuesta permanente de hogares: desarrollo actual y perspectivas. In: SEMINÁRIO INTERNACIONAL SOBRE MEDICIÓN DEL EMPLEO - INDEC. Buenos Aires, dez. 1995. Mimeografado.

PROGRAMA REGIONAL DEL EMPLEO PARA AMERICA LATINA E EL CARIBE - PREALC. Dinámica del subempleo en America Latina. Santiago do Chile: Cepal, ago. 1981. (Estudios e Informe)

TROYANO, A.A. Pesquisa de Emprego e Desemprego - metodologia, conceitos e aferições de resultados. São Paulo em Perspectiva São Paulo, Fundação Seade, v. 6, n. 2, p. 124-134, out./dez. 1992.

TROYANO, A.A. et al. A necessidade de uma nova conceituação de emprego e desemprego. São Paulo em Perspectiva, São Paulo, Fundação Seade, v. 1, n. 1, 1985.

Pesquisa de Emprego e Desemprego - operacionalização dos conceitos. São Paulo em Perspectiva, São Paulo, Fundação Seade, v. 1, n. 2, 1985.

Paula Montagner: Economista, Gerente de Análise e Estudos Especiais da Fundação Seade.

Atsuko Haga: Socióloga, Gerente de Métodos e Pesquisa da Fundação Seade. 